\title{
The W100 pocket on HIV-1 gp120 penetrated by b12 is not a target for other CD4bs monoclonal antibodies
}

\author{
Maria J Dueñas-Decamp ${ }^{1}$, Olivia J O'Connell ${ }^{1}$, Davide Corti ${ }^{2}$, Susan Zolla-Pazner ${ }^{3}$ and Paul R Clapham ${ }^{*}$
}

\begin{abstract}
Background: The conserved CD4 binding site (CD4bs) on HIV-1 gp120 is a major target for vaccines. It is a priority to determine sites and structures within the CD4bs that are important for inclusion in vaccines. We studied a gp120 pocket penetrated by W100 of the potent CD4bs monoclonal antibody (mab), b12. We compared HIV-1 envelopes and corresponding mutants that carried blocked W100 pockets to evaluate whether other CD4bs mabs target this site.

Findings: All CD4bs mabs tested blocked soluble CD4 binding to gp120 consistent with their designation as CD4bs directed antibodies. All CD4bs mabs tested neutralized pseudovirions carrying NL4.3 wild type (wt) envelope. However, only b12 failed to neutralize pseudoviruses carrying mutant envelopes with a blocked W100 pocket. In addition, for CD4bs mabs that neutralized pseudovirions carrying primary envelopes, mutation of the W100 pocket had little or no effect on neutralization sensitivity.

Conclusions: Our data indicate that the b12 W100 pocket on gp120 is infrequently targeted by CD4bs mabs. This site is therefore not a priority for preservation in vaccines aiming to elicit antibodies targeting the CD4bs.
\end{abstract}

Keywords: HIV, envelope, gp120, CD4 binding site, neutralization

\section{Findings}

The conserved CD4 binding site (CD4bs) on HIV-1 gp120 is a major target for the development of vaccines that aim to elicit neutralizing antibodies effective against diverse HIV-1 strains. It is, therefore, important to define sites and structures within the CD4bs that will need to be preserved in vaccines for the induction of neutralizing antibodies. The CD4 binding site (CD4bs) monoclonal antibody (mab), b12, targets a pocket on HIV-1 gp120 as part of its binding site. Thus, the organic rings of b12 W100 penetrate the pocket located immediately downstream from the CD4 binding loop (Figure 1). We showed previously that the presence of a combination of an arginine at residue 373 and a glycan at N386 appears to block the pocket and confer robust resistance to b12 for all five primary HIV-1 envelopes tested [1]. Even the highly sensitive

\footnotetext{
* Correspondence: paul.clapham@umassmed.edu

'Center for AIDS Research, Program in Molecular Medicine, University of

Massachusetts Medical School, Worcester, Massachusetts, MA 01605

Full list of author information is available at the end of the article
}

envelope of the T-cell line adapted NL4.3 strain became resistant when carrying the R373/N386 glycan combination. Single substitutions at 373 or that abrogate the glycan at N386 also affect sensitivity to b12 neutralization (our unpublished data and refs [2,3]). However, these changes (in the absence of the R373/N386 glycan combination) are frequently modest and envelope dependent. Here, we have investigated whether the combination of an arginine at residue 373 and a glycan at N386 (which confers resistance to b12) affects the sensitivity of neutralization by other CD4bs mabs.

We investigated 15 mabs that block sCD4 binding to gp120 including the potent neutralizing human mabs, b12 [4], HJ16 [5], VRC01 [6,7] and VRC03 [7] (Table 1). Mabs were selected for testing based on two criteria. First, we included mabs previously defined as targeting the CD4bs by their capacity to block gp120: CD4 binding or by crystallization as a complex with gp120. Second, we used CD4bs mabs that were available in sufficient quantities for the neutralization assays described. These

\section{Biomed Central}




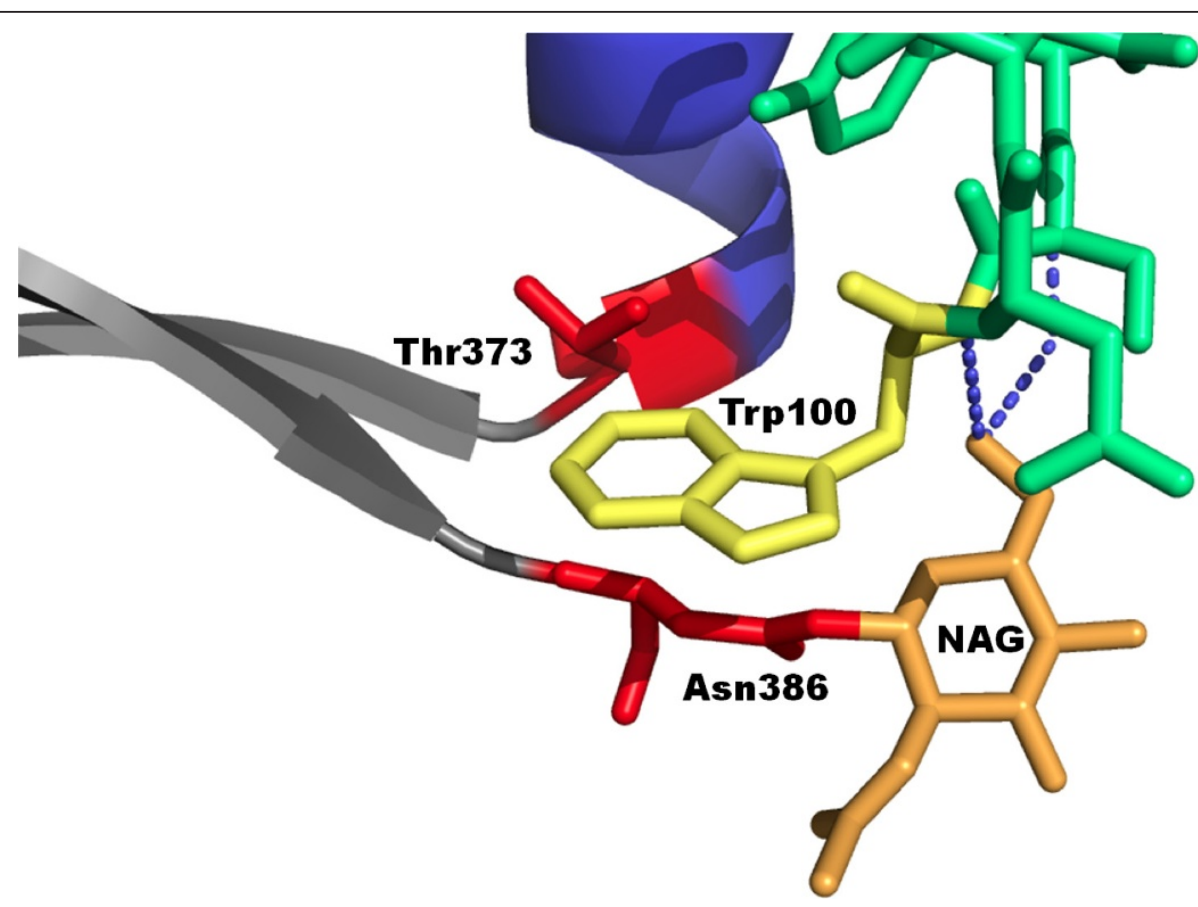

Figure 1 Proximal gp120 residues T373 and N386 (red) surround the pocket penetrated by the organic rings of b12's W100 (yellow). The longer side chain of R373 in combination with the glycan (orange) at N386 may block the pocket and prevent b12 (green) binding.

included mabs from the NIH AIDS Reagent Program, the UK Centre for AIDS Reagents, the Vaccine Research Center, NIH and from other sources (Table 1). We first confirmed that each of the mabs under investigation

Table 1 CD4 binding site monoclonal antibodies investigated

\begin{tabular}{|c|c|c|c|c|}
\hline Mab & Species & Epitope & Source & Ref. \\
\hline$\overline{b 12}$ & human & CD4bs & Polymun Sci. GmbH & {$[4]$} \\
\hline VRC01 & & & $\mathrm{NIH} V \mathrm{VRC}^{1}$ & {$[6]$} \\
\hline VRC03 & & & $\mathrm{NIH} \vee \mathrm{RC}$. & \\
\hline HJ16 & & & Humabs Inc. & {$[5]$} \\
\hline F105 & & & NIH AIDS Rea. Pr. ${ }^{2}$ & [19] \\
\hline $654-D$ & & & NIH AIDS Rea. Pr. & {$[20]$} \\
\hline $15 e$ & & & UK/EU CFAR ${ }^{3}$ & {$[21]$} \\
\hline M14 & & & UKJEU CFAR & {$[22]$} \\
\hline Gp68 & & & UKJEU CFAR & {$[23]$} \\
\hline 1027 & & & Dr Zolla-Pazner & \\
\hline 1008 & & & Dr Zolla-Pazner & \\
\hline 1570 & & & Dr Zolla-Pazner & {$[24]$} \\
\hline 1595 & & & Dr Zolla-Pazner & {$[24]$} \\
\hline 1599 & & & Dr Zolla-Pazner & {$[24]$} \\
\hline ICR39.13 & rat & & UKJEU CFAR & {$[25]$} \\
\hline $17 b$ & human & CD4i & NIH AIDS Rea. Pr. & {$[9]$} \\
\hline
\end{tabular}

1. NIH Vaccine Research Center.

2. NIH AIDS Reagent Program.

3. Programme EVA Centre for AIDS Reagents, UK. blocked sCD4 binding to recombinant gp120 in ELISA assays (Additional File 1: Figure 1). We next tested the capacity of each mab to neutralize NL4.3 wt and NL4.3 T373R (which combines R373 with the glycan already present at N386). NL4.3 is ideal for investigating whether mutation of the W100 pocket affects neutralization since it is highly sensitive to b12 and to each of the CD4bs mabs investigated here. Neutralization assays were done using pseudovirions carrying envelopes from NL4.3wt and NL4.3 T373R (NL4.3-R). HeLa TZM-bl cells were used as targets, and residual infectivity was assessed by measuring luciferase activity [8]. We found that neutralization of NL4.3 by each of the mabs was unaffected or only weakly affected by the R373/N386 glycan combination (Figure 2). Briefly, NL4.3-R appeared marginally more sensitive to mab $15 \mathrm{e}$, yet modestly more resistant to 1595 . In addition, the T373R/N386 glycan combination conferred increased sensitivity to the CD4i mab $17 \mathrm{~b}$, perhaps indicating a modest shift in envelope conformation towards the CD4-bound form [9].

The NL4.3 envelope is derived from a T-cell line adapted HIV-1 and may not accurately represent the structures of primary envelopes in vivo. We, therefore, evaluated whether mutation of the W100 pocket affected the sensitivity of primary envelopes. For this experiment, we used AD8 [10], JR-CSF, and JRFL [11] envelopes that were derived from limited culture primary isolates as well as LN40 and B33 that were 


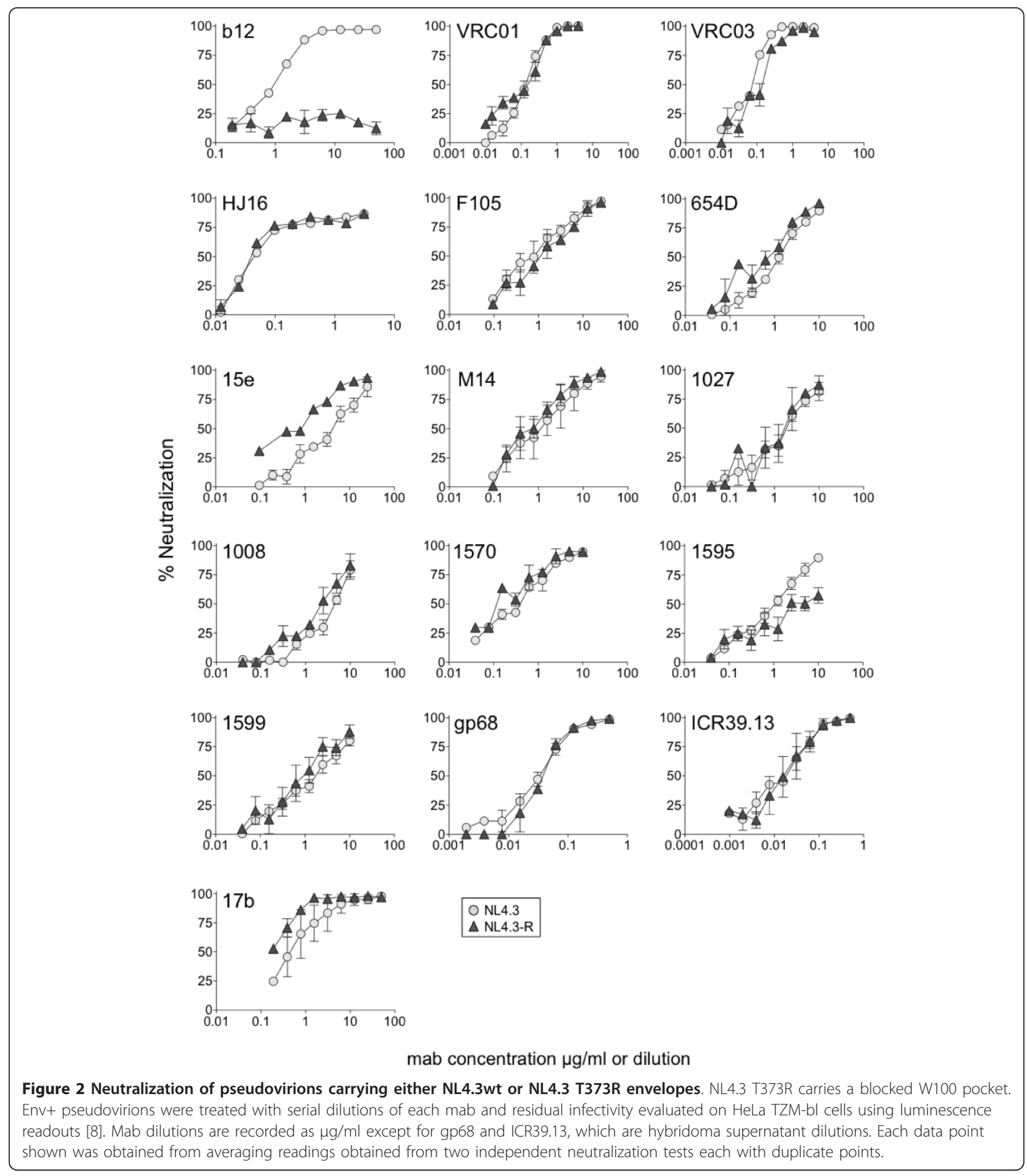

amplified directly from lymph node and brain tissue of an AIDS patient, respectively [12]. We tested the sensitivity of envelopes with and without a mutated W100 pocket to neutralization by the potent and broad CD4bs mabs, VRC01 and VRC03 and compared with sensitivity to b12 (Figure 3). For AD8, JR-CSF and JR-FL, the mutated envelopes carried a single substitution to R373 to make the R373/N386 glycan combination. For B33, a double substitution introduced R373/N386; while for LN40 (which naturally carries R373/N386), we substituted K373/D386 to reflect the sequence of the B33 envelope. For all five of these primary envelopes, the 


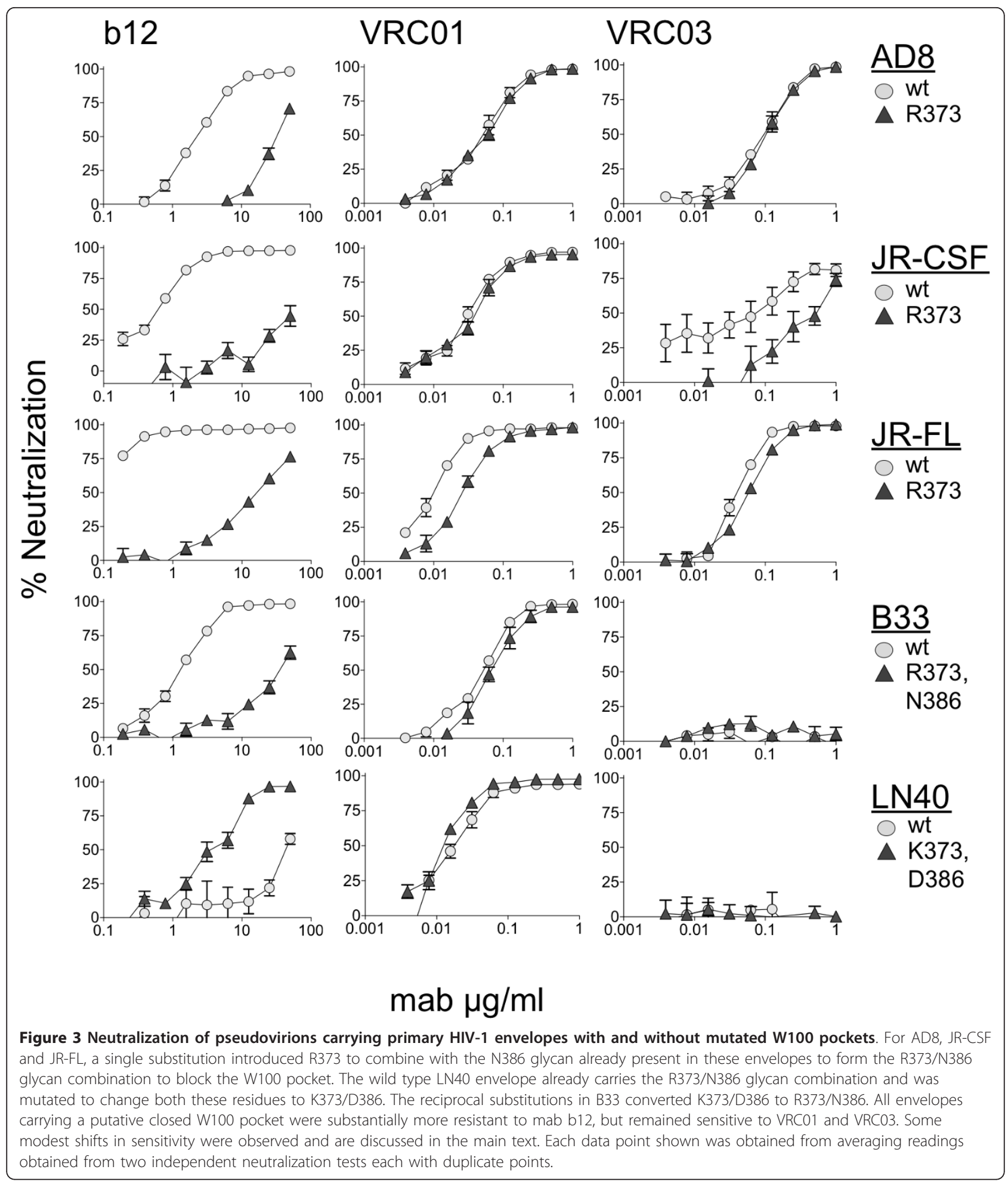

presence of R373/N386 conferred a dramatic reduction in sensitivity to b12 as expected (Figure 3, left panels). In contrast, for both VRC01 and VRC03, a mutated W100 pocket failed to confer more than minor shifts in neutralization sensitivity. The mutated JR-FL envelope conferred a small shift to increased resistance to VRC01, while JR-CSF became modestly more resistant to VRC03. In contrast, B33 and LN40 wt and mutant envelopes were resistant to VRC03. Together, our data show that the combination of R373 and the N386 glycan 
does not confer more than modest effects on neutralization by 14 CD4bs mabs contrasting with robust resistance consistently conferred for b12.

Recently, further CD4bs mabs, e.g. 3BNC60 [13] and VRC-PG04 [14] have been reported [13-15]. Like VRC01, VRC03, and HJ16 (studied here), they were derived from so called 'elite neutralizers', HIV-1+ subjects who carried potent neutralizing antbodies active against diverse viral strains. These new mabs are highly potent and have binding specificities that focus on similar gp120 residues to that of VRC01 [6], which (as confirmed here) does not penetrate the W100 pocket on gp120. The crystal structure of mab 3BNC60 verifies a structure where predicted gp120 contact residues are conserved with those of VRC01 [13], while a structure of mab VRC-PG04 complexed with a gp120 core shows the same for that mab and confirms no interaction with the W100 pocket on gp120. Diskin et al. also reported that NIH45-46 conferred even more potent neutralization than VRC01. However, the increased potency of this mab was due to increased contact with the gp120 inner domain and bridging sheet determinants without targeting the W100 pocket [16].

In summary, we investigated whether the W100 pocket on gp120 (a critical target for mab b12) is required for HIV-1 neutralization by other CD4bs mabs. We found that neutralization of pseudovirions carrying primary or T-cell line adapted HIV-1 envelopes was either unaffected or only marginally shifted by the presence of a mutated W100 pocket. These observations contrasted with neutralization by b12, which was severely curtailed by the presence of a mutated W100 pocket for all six HIV-1 envelopes tested. Our data indicate that the W100 pocket on gp120 is not a frequent target among CD4bs mabs and is not required for potent neutralization of diverse primary strains of HIV-1 via the CD4bs.

\section{Availability of supporting data}

The data sets supporting the results of this article are available in the Dryad repository http://dx.doi.org/ $10.5061 /$ dryad.66h5g23t.

\section{Additional material}

Additional file 1: Figure 1. Inhibition of CD4 binding to gp120. ELISAs were carried out to confirm that CD4bs mabs blocked sCD4 binding to gp120. For human mabs (except for gp68), serial $(0-8 \mu \mathrm{g} / \mathrm{ml})$ antibody dilutions were added to saturating immobilized amounts of IIIB gp120 (Immunodiagnostics Inc.) captured with a sheep anti-gp120 C-terminal peptide (Alto Bio Reagents Inc.). Appropriate sCD4 dilutions were then added and bound SCD4 detected using mouse mab, OKT4, followed by an anti-mouse IgG-HRP conjugate (Thermo Scientific Inc.). Mabs gp68 and ICR39.13 were in the form of hybridoma culture supernatant and were added at 1:2 to 1:16 dilutions. ICR39.13 is a rat antibody and was evaluated by competition with PRO542 (CD4-lgG) [17], followed by and ant-human IgG-HRP conjugate. All mabs designated as binding the
CD4bs blocked sCD4 binding to recombinant gp120. Most blocked sCD4 highly efficiently, although neither VRC03 nor F105 was particularly effective. Since the structures of VRC03 and F105 bound to gp120 irrevocably prove their specificity for the CD4bs $[14,18]$, the reasons for weaker sCD4 inhibition are unclear. We also tested the CD4i mab, 17b, as a control. As expected, this mab failed to block SCD4 binding to gp120.

\section{List of abbreviations}

None.

\section{Acknowledgements}

We thank Paul Peters for his insightful comments and input for this study. We also thank John Mascola (Vaccine Research Center, NIAID) and Robin Weiss (UCL, London) for supportive comments and for help in obtaining mabs VRC01, VRC03 and HJ16 respectively. We thank James Robinson (Tulane University School of Medicine) for providing mab 17b. Our work was supported by NIH grants R01s MH64408, Al089334 and P01 Al082274. We also wish to thank the University of Massachusetts Medical School Center for AIDS Research (CFAR), the NIH AIDS Research and Reference Reagent Program, the Vaccine Research Center, NIH and the Centre for AIDS Reagents, NIBSC, UK, for services and reagents.

\section{Author details}

${ }^{1}$ Center for AIDS Research, Program in Molecular Medicine, University of Massachusetts Medical School, Worcester, Massachusetts, MA 01605. ${ }^{2}$ Humabs Biomed SA, Bellinzona, $\mathrm{CH}-6500$, Switzerland. ${ }^{3}$ Department of Pathology, New York University Langone School of Medicine, New York, NY 10016.

\section{Authors' contributions}

MJD-D helped conceive the study, carried out the neutralization assays and helped write the manuscript. OJO'C carried out the ELISAs and helped interpret their results. DC provided mab, HJ16, and critical discussion of the data. SZ-P provided several mabs and critical discussion of the data and manuscript. PRC conceived the study and wrote the manuscript. All authors read and approved the final manuscript

\section{Competing interests}

The authors declare that they have no competing interests.

Received: 19 July 2011 Accepted: 27 January 2012

Published: 27 January 2012

\section{References}

1. Duenas-Decamp MJ, Peters P, Burton D, Clapham PR: Natural resistance of human immunodeficiency virus type 1 to the CD4bs antibody b12 conferred by a glycan and an arginine residue close to the CD4 binding loop. J Virol 2008, 82:5807-5814.

2. Pantophlet $R$, Ollmann Sapphire E, Poignard P, Parren PW, Wilson IA, Burton DR: Fine mapping of the interaction of neutralizing and nonneutralizing monoclonal antibodies with the CD4 binding site of human immunodeficiency virus type $1 \mathrm{gp} 120$. J Virol 2003, 77:642-658.

3. Sanders RW, van Anken E, Nabatov AA, Liscaljet IM, Bontjer I, Eggink D, Melchers M, Busser E, Dankers MM, Groot F, Braakman I, Berkhout B, Paxton WA: The carbohydrate at asparagine 386 on HIV-1 gp120 is not essential for protein folding and function but is involved in immune evasion. Retrovirology 2008, 5:10.

4. Zhou T, Xu L, Dey B, Hessell AJ, Van Ryk D, Xiang SH, Yang X, Zhang MY, Zwick MB, Arthos J, Burton DR, Dimitrov DS, Sodroski J, Wyatt R, Nabel GJ, Kwong PD: Structural definition of a conserved neutralization epitope on HIV-1 gp120. Nature 2007, 445:732-737.

5. Corti D, Langedijk JP, Hinz A, Seaman MS, Vanzetta F, FernandezRodriguez BM, Silacci C, Pinna D, Jarrossay D, Balla-Jhagjhoorsingh S, Willems B, Zekveld MJ, Dreja H, O'Sullivan E, Pade C, Orkin C, Jeffs SA, Montefiori DC, Davis D, Weissenhorn W, McKnight A, Heeney JL, Sallusto F, Sattentau QJ, Weiss RA, Lanzavecchia A: Analysis of memory B cell responses and isolation of novel monoclonal antibodies with 
neutralizing breadth from HIV-1-infected individuals. PLoS One 2010, 5: e8805.

6. Zhou T, Georgiev I, Wu X, Yang ZY, Dai K, Finzi A, Do Kwon Y, Scheid J, Shi W, Xu L, Yang Y, Zhu J, Nussenzweig MC, Sodroski J, Shapiro L, Nabel GJ, Mascola JR, Kwong PD: Structural Basis for Broad and Potent Neutralization of HIV-1 by Antibody VRC01. Science 2010, 330:1775-1787.

7. Li Y, O'Dell S, Walker LM, Wu X, Guenaga J, Feng Y, Schmidt SD, McKee K, Louder MK, Ledgerwood JE, Graham BS, Haynes BF, Burton DR, Wyatt RT, Mascola JR: Mechanism of Neutralization by the Broadly Neutralizing HIV-1 Monoclonal Antibody VRC01. J Virol 2011, 85:8954-8967.

8. Peters PJ, Duenas-Decamp MJ, Sullivan WM, Brown R, Ankghuambom C, Luzuriaga K, Robinson J, Burton DR, Bell J, Simmonds P, Ball J, Clapham P: Variation in HIV-1 R5 macrophage-tropism correlates with sensitivity to reagents that block envelope: CD4 interactions but not with sensitivity to other entry inhibitors. Retrovirology 2008, 5:5.

9. Kwong PD, Wyatt R, Robinson J, Sweet RW, Sodroski J, Hendrickson WA: Structure of an HIV gp120 envelope glycoprotein in complex with the CD4 receptor and a neutralizing human antibody. Nature 1998, 393:648-659.

10. Theodore TS, Englund G, Buckler-White A, Buckler CE, Martin MA, Peden KW: Construction and characterization of a stable full-length macrophage-tropic HIV type 1 molecular clone that directs the production of high titers of progeny virions. AIDS Res Hum Retroviruses 1996, 12:191-194.

11. Koyanagi Y, Miles S, Mitsuyasu RT, Merrill JE, Vinters HV, Chen IS: Dual infection of the central nervous system by AIDS viruses with distinct cellular tropisms. Science 1987, 236:819-822.

12. Peters PJ, Bhattacharya J, Hibbitts S, Dittmar MT, Simmons G, Bell J, Simmonds P, Clapham PR: Biological analysis of human immunodeficiency virus type 1 R5 envelopes amplified from brain and lymph node tissues of AIDS patients with neuropathology reveals two distinct tropism phenotypes and identifies envelopes in the brain that confer an enhanced tropism and fusigenicity for macrophages. J Virol 2004, 78:6915-6926.

13. Scheid JF, Mouquet H, Ueberheide B, Diskin R, Klein F, Olivera TY, Pietzsch J, Fenyo D, Abadir A, Velinzon K, Hurley A, Myung S, Boulad F, Poignard P, Burton D, Pereyra F, Ho DD, Walker BD, Seaman MS, Bjorkman PJ, Chait BT, Nussenzweig MC: Sequence and Structural Convergence of Broad and Potent HIV Antibodies That Mimic CD4 Binding. Science 2011, 333:1633-1637

14. Wu X, Zhou T, Zhu J, Zhang B, Georgiev I, Wang C, Chen X, Longo NS, Louder M, McKee K, O'Dell S, Perfetto S, Schmidt SD, Shi W, Wu L, Yang Y, Yang ZY, Yang Z, Zhang Z, Bonsignori M, Crump JA, Kapiga SH, Sam NE, Haynes BF, Simek M, Burton DR, Koff WC, Doria-Rose N, Connors M, Mullikin JC, Nabel GJ, Roederer M, Shapiro L, Kwong PD, Mascola JR: Focused Evolution of HIV-1 Neutralizing Antibodies Revealed by Structures and Deep Sequencing. Science 2011, 333:1593-1602.

15. Clapham PR, Lu S: Vaccinology: precisely tuned antibodies nab HIV. Nature 2011, 477:416-417.

16. Diskin R, Scheid JF, Marcovecchio PM, West AP Jr, Klein F, Gao H, Gnanapragasam PN, Abadir A, Seaman MS, Nussenzweig MC, Bjorkman PJ: Increasing the Potency and Breadth of an HIV Antibody by Using Structure-Based Rational Design. Science 2011, 334:1289-1293.

17. Jacobson JM, Lowy I, Fletcher CV, O'Neill TJ, Tran DN, Ketas TJ, Trkola A, Klotman ME, Maddon PJ, Olson WC, Israel RJ: Single-dose safety, pharmacology, and antiviral activity of the human immunodeficiency virus (HIV) type 1 entry inhibitor PRO 542 in HIV-infected adults. J Infect Dis 2000, 182:326-329.

18. Chen L, Kwon YD, Zhou T, Wu X, O'Dell S, Cavacini L, Hessell AJ, Pancera M, Tang M, Xu L, Yang ZY, Zhang MY, Arthos J, Burton DR, Dimitrov DS, Nabel GJ, Posner MR, Sodroski J, Wyatt R, Mascola JR, Kwong PD: Structural basis of immune evasion at the site of CD4 attachment on HIV-1 gp120. Science 2009, 326:1123-1127.

19. Wilkinson RA, Piscitelli C, Teintze M, Cavacini LA, Posner MR, Lawrence CM: Structure of the Fab fragment of $\mathrm{F} 105$, a broadly reactive anti-human immunodeficiency virus (HIV) antibody that recognizes the CD4 binding site of HIV type $1 \mathrm{gp} 120$. J Virol 2005, 79:13060-13069.

20. Laal S, Burda S, Gorny MK, Karwowska S, Buchbinder A, Zolla-Pazner S: Synergistic neutralization of human immunodeficiency virus type 1 by combinations of human monoclonal antibodies. J Virol 1994, 68:4001-4008.
21. Ho DD, McKeating JA, Li XL, Moudgil T, Daar ES, Sun NC, Robinson JE: Conformational epitope on gp120 important in CD4 binding and human immunodeficiency virus type 1 neutralization identified by a human monoclonal antibody. J Virol 1991, 65:489-493.

22. Zhang MY, Dimitrov DS: Novel approaches for identification of broadly cross-reactive HIV-1 neutralizing human monoclonal antibodies and improvement of their potency. Curr Pharm Des 2007, 13:203-212.

23. Schutten M, MCKnight A, Huisman RC, Thali M, McKeating JA, Sodroski J, Goudsmit J, Osterhaus AD: Further characterization of an antigenic site of HIV-1 gp120 recognized by virus neutralizing human monoclonal antibodies. AIDS 1993, 7:919-923.

24. Jeffs SA, Gorny MK, Williams C, Revesz K, Volsky B, Burda S, Wang XH, Bandres J, Zolla-Pazner S, Holmes H: Characterization of human monoclonal antibodies selected with a hypervariable loop-deleted recombinant HIV-1(IIIB) gp120. Immunol Lett 2001, 79:209-213.

25. McKeating JA, Thali M, Furman C, Karwowska S, Gorny MK, Cordell J, Zolla Pazner S, Sodroski J, Weiss RA: Amino acid residues of the human immunodeficiency virus type I gp120 critical for the binding of rat and human neutralizing antibodies that block the gp120-sCD4 interaction. Virology 1992, 190:134-142.

doi:10.1186/1742-4690-9-9

Cite this article as: Dueñas-Decamp et al:: The W100 pocket on HIV-1 gp120 penetrated by b12 is not a target for other CD4bs monoclonal antibodies. Retrovirology 2012 9:9.

\section{Submit your next manuscript to BioMed Central and take full advantage of:}

- Convenient online submission

- Thorough peer review

- No space constraints or color figure charges

- Immediate publication on acceptance

- Inclusion in PubMed, CAS, Scopus and Google Scholar

- Research which is freely available for redistribution

Submit your manuscript at www.biomedcentral.com/submit
Biomed Central 